\title{
Designing resilient regions by applying Blue-Green Infrastructure concepts
}

\author{
Z. Ghofrani, V. Sposito \& R. Faggian \\ Centre for Regional and Rural Futures (CeRRF), Deakin University, \\ Australia
}

\begin{abstract}
In Australia, weather extremes (droughts and floods) are an accepted component of coupled human-environment systems. Australia is the driest inhabited continent on earth and also has the greatest annual rainfall and run-off variability. Competition for water between the environment, agriculture and domestic uses is intense and the cause of much public debate. It is not unusual for parts of Australia to transition quickly from a state of extreme water scarcity to one of severe flooding. In fact, floods cause more damage in Australia than any other natural disaster. Climate change will exacerbate the situation through increased frequency and intensity of heavy rainfall events and also more intense and longer-lasting droughts. The combination of drought followed by intense rainfall increases the risk of severe flooding, with impacts on civil infrastructure (road and bridge washouts, damage to houses), and impacts on agriculture (soil erosion and destruction of crops and livestock).

Structural flood mitigation activities in Australia, such as the construction of levees, was initially driven by private landholders. These measures were often not well planned or integrated at larger scales and therefore have been viewed with some suspicion. More recently, non-structural (land planning, emergency management) approaches have become the key flood mitigation measure. In contrast, The Netherlands takes a structural approach through concepts like Blue-Green Infrastructure (BGI), with the aim of "giving the flood a pathway". In this context, structural interventions in the landscape provide alternative pathways for flood water, slowing the waters progress such that flood damage is mitigated. Our research focuses on the feasibility of implementing BGI in Australia, considering the costs and benefits in terms of the biophysical environment, infrastructure and socioeconomic systems, in order to increase the resilience of rural and regional com-
\end{abstract}


munities. The research will inform strategic and statutory planning at the regional level.

Keywords: sustainable region, climate change adaptation, Blue-Green Infrastructure, disaster management.

\section{Introduction}

Australia faces a variety of natural disasters such as floods, severe storms, and bush-fires in a regular basis. In fact, Australia has long been called 'the land of droughts and flooding rains' [1]. These disasters have a major social, ecological, financial, and political impact on the society. While the risk cannot be entirely eliminated, some of the impacts of natural disasters can be mitigated [2].

Since 1790, when the first flood fatality was documented in Australia, there have been more than 2300 flood-related losses [3]. During the period of 1967 to 1999 , the total estimated cost of flooding is $\$ 10.4$ billion, equating to an average annual cost of $\$ 314$ million [3]. In this period floods with $29 \%$ of the total cost, followed by severe storms with $26 \%$, and tropical cyclones with $24 \%$ have been the most costly natural disaster types (Table 1). In Figure 1, the six most important disasters in terms of costs are shown [3]. It illustrates the breakdown of the total and insurance costs by the type of natural disaster during 1967 to 1999 [3]. An evaluation with financial costs in comparison with other natural disasters approves that flooding is the most costly natural disaster in Australia [3].

Heavy rainfall is the predominant cause of flooding in Australia, however storm tide, tsunami, extreme tides, dam break or snow melt can also lead to flooding. Riverine and/or flash flooding, local drainage problems, and a rise of groundwater level even above the natural surface, can be a consequence of heavy rainfall.

Table 1: Average annual cost of natural disasters by state territory (2001) [3].

\begin{tabular}{cccccccc}
\hline State & Flood & Severe storm & Cyclone & Earthquake & Bush-fire & Landslide & Total \\
\hline NSW & 128.4 & 195.8 & 0.5 & 141.2 & 16.8 & 1.2 & 484.1 \\
QLD & 111.7 & 37.3 & 89.9 & 0.0 & 0.4 & 0.0 & 239.2 \\
NT & 8.1 & 0.0 & 134.2 & 0.3 & 0.0 & 0.0 & 142.6 \\
VIC & 38.5 & 22.8 & 0.0 & 0.0 & 32.4 & 0.0 & 93.6 \\
WA & 2.6 & 11.1 & 41.6 & 3.0 & 4.5 & 0.0 & 62.7 \\
SA & 18.1 & 16.2 & 0.0 & 0.0 & 11.9 & 0.0 & 46.2 \\
TAS & 6.7 & 1.1 & 0.0 & 0.0 & 11.2 & 0.0 & 18.9 \\
ACT & 0.0 & 0.1 & 0.0 & 0.0 & 0.0 & 0.0 & 0.2 \\
Total & 314.0 & 284.4 & 266.2 & 144.5 & 77.2 & 1.2 & 1087.5 \\
\hline Proportion(\%) & 28.9 & 26.2 & 24.5 & 13.3 & 7.1 & 0.1 & 100.0 \\
\hline
\end{tabular}




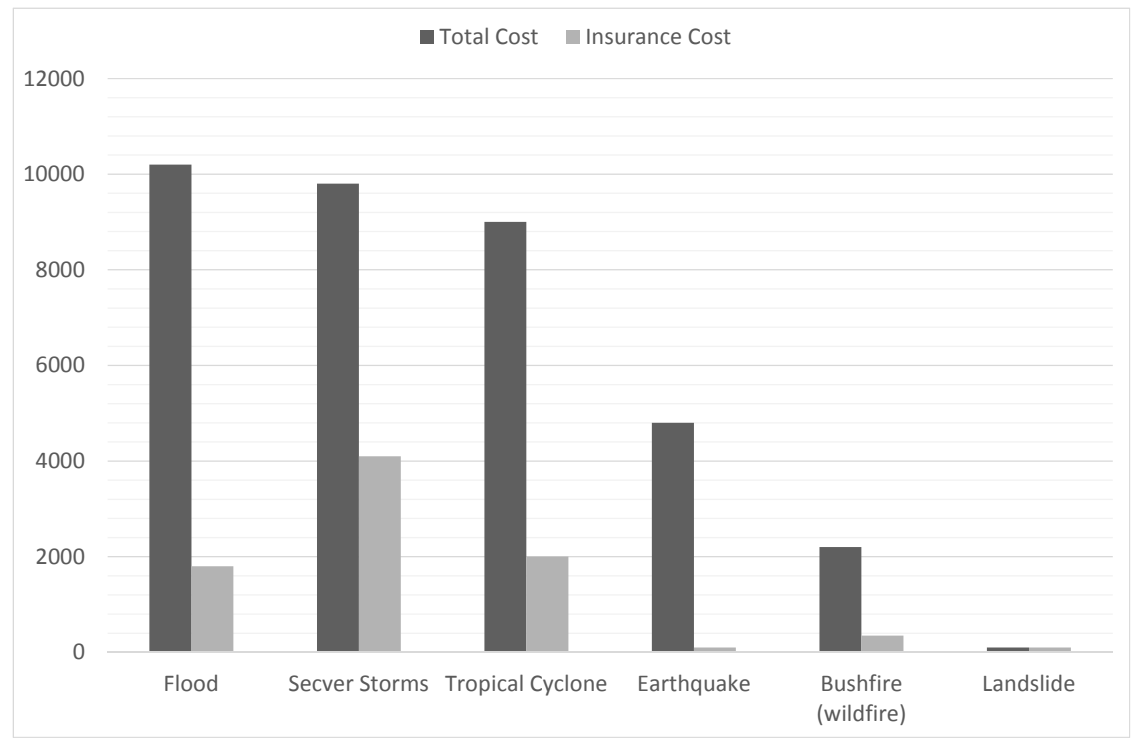

Figure 1: Total and insurance costs based on the type of natural disaster (2001) [3].

A number of reasons such as spatial distribution, volume, intensity and duration of precipitation over the catchment; ground cover; catchment situations prior to the rainfall event; groundwater tables; topography; tidal influence; and the capacity of the watercourse or stream network to deliver the run-off, influence whether or not a flood will occur. Mechanisms which hinder flows (such as detention basins, and dams), or confine flows (such as levees), and development within the catchment and floodplain, also influence whether or not a flood will occur [2]. Figure 2 illustrates the spatial distribution of long-duration slow-rise floods and short-duration rapid onset floods. A natural separation of slower, broader rivers flowing west from quicker, narrower coastal rivers flowing east is provided by the Great Dividing Range in eastern Australia [2].

Climate change will exacerbate the situation through increased frequency and intensity of heavy rainfall events and also more intense and longer-lasting droughts. The combination of drought followed by intense rainfall increases the risk of severe flooding, with impacts on civil infrastructure (road and bridge washouts, damage to houses), and impacts on agriculture (soil erosion and destruction of crops and livestock). However, it should also be remembered that floods are an important part of ecosystem function in Australia and introducing the concept of potentially harvesting flood waters for beneficial uses (like irrigation and agriculture) is vital.

Since floods are limited to definable areas and people directly influence flood risk, the potential to achieve substantial advantages by effective control of flood risk is greater than for other hazards although, vulnerability is escalated through 


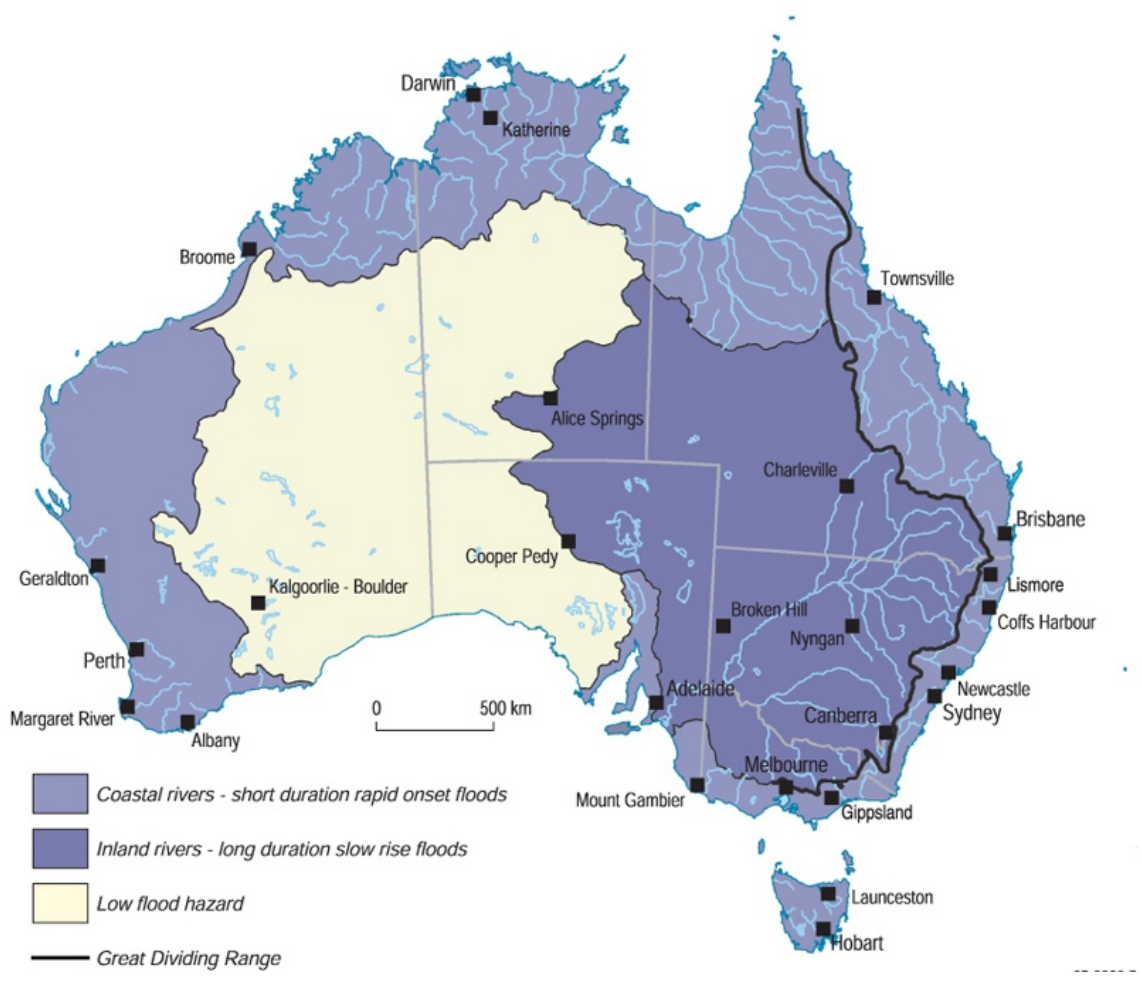

Figure 2: The spatial distribution of floods in Australia (2007) [2].

development in floodplains. Structural flood mitigation activities in Australia, such as the construction of levees, was initially driven by private landholders. These measures were often not well planned or integrated at larger scales and therefore have been viewed with some suspicion. More recently, non-structural (land planning, emergency management) approaches have become the key flood mitigation measure. In contrast, The Netherlands takes a structural approach through concepts like Blue-Green Infrastructure (BGI), with the aim of "giving the flood a pathway". In this context, structural interventions in the landscape provide alternative pathways for flood water, slowing the waters progress such that flood damage is mitigated.

Our research focusses on the feasibility of implementing BGI to gain the flood benefits and minimize its dangers in Australia, considering the costs and benefits in terms of the biophysical environment, infrastructure and socio-economic systems, in order to increase the resilience of rural and regional communities [4]. This paper is organized as follows: Section 2 describes the potential impact of climate change. Section 3 represents adaptation and disaster management rules. Section 4 describes BGI feasibility set up. Finally, in section 5, our conclusions are drawn. 


\section{Potential impact of climate change}

The variability and potential impact of climate change on floods is being investigated at various levels. Based on current projections, the average rainfall is likely to decline in the southern parts of Australia and rise in the north. Moreover, the intensity of extreme daily rainfall events is expected to increase in many parts of the country [5-8]. Rainfall intensity plays an important role in the magnitude of flooding, as antecedent circumstances do.

Climate change will come on top of natural variability, and is estimated to intensify natural disasters of drought and flood. Due to global warming, flood characteristics are expected to change and we can no longer trust the historical data to predict floods [9]. Moreover, the magnitude and frequency of floods in the near future is estimated to vary across Australia, due to changing climate. Hydrologic time series (e.g. flood data) can no more be supposed to be stationary, since it has been recognized that changing climate will have distinct influences on the rainfall run-off process. Therefore, it has serious implications in regional flood estimations, since these are based on historical data, which can no more be taken to demonstrate the future under a changing climate scenario. A failure to take climate change into consideration will undermine the effectiveness of the theory of return period, and can result in overestimation/underestimation of flood magnitude and frequency, and consequently will have significant implications on the operation and design of water infrastructure [10].

A rise of between 1.4 and $5.8^{\circ} \mathrm{C}$ above 1990 levels in the global mean temperature is expected by 2100 [11]. Consequently, due to variations in sea level rise and precipitation, flood patterns will change. As higher sea surface temperatures lead to more evaporation, and warm air can retain more water vapour, therefore, increased precipitation intensity is expected. Changing circulation patterns will impact rainfall distribution [11]. Sea levels in Australia are increasing, but at different degrees. The north and north-west Australia have been increasing 7-11 mm per year, whereas, the oceans on the central east and southern coasts of Australia are increasing at a rate of about $3 \mathrm{~mm}$ per year - equal to the global average. At this point, the increases are associated principally with warming of ocean waters, causing them to increase in volume [9]. Sea level rise and changing precipitation patterns are not the only factors that influence flooding. Others include soil movements (due to increased erosion), storm surge, population growth, urbanisation (related to impermeable surfaces that increases water runoff), land subsidence, vegetation cover, landscape modifications (e.g. levees), and soil moisture level. Many of these factors to some degree can also be related to climate change [9].

\section{Adaptation and disaster management}

Increased exposure to flood will have a significant influence on life, infrastructure, property, environment, health (including injury and exposure to chemical and pathogenic pollutants), livelihoods and society [12]. According to a report by 
the Commonwealth Scientific and Industrial Research Organization (CSIRO), the number of Australians faced with risk of flooding will be increased by $100 \%$, if average global temperatures rise between 1 and 2 degrees [13]. There will be increased likelihood of death and injury, and property damage is expected to be substantial. A sea level rise of $1.1 \mathrm{~m}$ could potentially expose more than \$226 billion worth of Australian coastal properties to flooding and erosion [9].

Thus, we can adapt to climate change and reduce the destruction, or we can fail to adapt and expose much more serious consequences. We will shape the future in significant ways based on how we respond to this challenge. The severity of the pressures to which the world will be exposed is determined by magnitude and pace of the climate change. To enable current and future generations to better deal with and adopt to the resulting hazards, thereby decreasing the harms and danger, the best solution is slowing the pace of human caused climate change, with the aim of finally stopping it [14].

Dealing with the risks of climate change includes mitigation and adaptation decisions with implications for future environments, generations, and economies [15]. Efficient risk adaptation and reduction approaches take into account the dynamics of exposure and vulnerability and their associations with climate change, sustainable development, and socioeconomic processes [15]. Corresponding actions across levels, from individuals to governments should be applied to improve adaptation planning and implementation. Attempts of local and subnational governments can be managed by national government through supporting economic diversification, providing data, plan and lawful structures, providing financial support, and protecting vulnerable groups.

Reducing vulnerability and exposure to present climate variability is a first step towards adaptation to future climate change. Strategies that include actions with co-benefits for other objectives, can increase resilience across a range of possible future climates while helping to improve human health, social and economic wellbeing, environmental quality, and livelihoods [15].

\section{Existing measures to mitigate flood consequences}

Flood hazard mitigation strategies can be applied as either non-structural or structural measures, based on the specific situation [16]. These measures involve preventing the negative consequences and managing the effects of flooding. Non-structural techniques, such as land use legislation, hydrologic forecasting and warning, education, and flood insurance, serve as preventive measures for decreasing flood hazards [17].

However, structural measures, such as riverbank protection, afforestation, high flow diversion, channel modification, and levees construction, can be applied to reduce flood danger by decreasing water level or extent of the area of flooding, and volume of run-off. Structural measures are recommended in situations where it is vital to protect land adjoining a catchment from inundations due to an existing flood risk, or in which sections of adjacent areas are located about the maximum 
flood level. Flood hazards for these mentioned types of areas are decreased, by implementing structural measures [17].

\section{Feasibility of Blue-Green Infrastructure}

BGI is an interconnected network of natural and designed landscape components, including water bodies and green and open spaces, which provide multiple functions such as: (i) water storage for irrigation and industry use, (ii) flood control, (iii) wetland areas for wildlife habitat or water purification, among many others. Operation of regional ecosystem functions to increase regional climate resilience in Australia can be realized by considering various characteristics affect the possibilities for retrofitting BGI [18]. The most important advantages of BGI are firstly its efficacy for flood mitigation, and secondly its cost effectiveness relative to other approaches.

As an increase in frequency and magnitude of intense precipitation events in the future is predicted, we shall expect more floods and the damage they cause $[19,20]$. The flood risk will be further exacerbated due to the increase in urbanization and economic growth. Therefore, a demand for new and inventive research to decrease the possibility and consequences of flooding is inevitable. Moreover, the research should help to adopt new flood risks imposed by climate change and economic development $[12,20]$.

A most important antecedent to BGI is the extensive spatial planning work and research undertaken in The Netherlands over many decades, which has recently focused on the spatial dimension of climate change through the LANDS project. BGI can exist at various geographic levels (e.g. region, city-region, urban, river basin/catchment/watershed, and site) and functions across jurisdictional boundaries. Therefore, BGI is not limited to urban spaces, but its planning can be considered at multiple levels and in various planning contexts such as urban, peri-urban, regional, and rural planning. Despite its application at multiple levels, we are particularly interested in this research at the river basin (or watershed or catchment) level in regional/rural systems [4].

A possible decision framework for feasibility of BGI in Australia is as follows.

\subsection{Practical feasibility evaluation}

This feasibility study needs the collection of environmental and watershed data.

\subsubsection{Ecological features}

Practical feasibility of BGI execution in Australia, depends on ecological characteristics which include geomorphologic conditions that define the amount of infiltration and retention in the soil (such as landscape slope, dynamics, groundwater depth, and soil type), and climatic conditions which impact the process of evapotranspiration and cooling (like solar radiation and temperature) [21-23]. Depending on the Australian ecosystem, BGI performance is affected by one or several of these ecological features. 


\subsubsection{Situation for BGI in the watershed}

While checking the conditions for feasibility of BGI in our case in Australia, we have to consider how BGI will influence regional and local groundwater levels. In these systems, soil water infiltrates and drainage of shallow groundwater by sewers happens, when regional and local groundwater levels become higher than the depth of the drainage or sewer system in the soil [22-25]. Moreover, at the beginning of the planning procedure it is crucial to evaluate the location of the BGI in the catchment. Applying BGI can impact the hydrological load downstream, when the position is upstream in the catchment [26].

\subsection{Site feasibility evaluation}

This is a data-extensive phase that utilizes basic field data.

\subsubsection{Regional characteristics}

Regional characteristics in Australia such as land cover features, soil pollution, ownership, and existence of subsurface infrastructure play an important role in site complexity [26,27]. The more complex the situation is, the more challenging it is to apply BGI. We have to consider density of the regional area (land cover characteristics), as well as subsurface infrastructure, soil and groundwater pollution while choosing the BGI. Moreover, as it is more challenging to implement BGI on private property rather than public one, ownership is one the most important obstacles in implementing the BGI in regional areas [26, 28].

\subsection{Integrated evaluation}

For generating regional resilience to flooding and drought, and in order to optimally use BGI, a composition of effective and cost efficient measures based on the characteristics of the site should be implemented.

\subsubsection{Considering multiple ecosystem parameters}

Some main parameters such as: evapotranspiration on a hot day for cooling, retention for extreme precipitation events, peak discharge reduction, seasonal water storage at beginning of drought period, extra groundwater recharge, and the influence of BGI on water quality should be identified in order to assess the contribution of the BGI [18].

\subsubsection{Hydrologic interconnected network}

BGI is significantly different from conventional 'hard' built infrastructure such as roads, sewerage and drainage systems, and utility lines. Connectivity is a key concept for BGI, since many of the benefits of BGI can be truly realized by an interconnected network of its constituting components. Storage and infiltration components can get interconnected via linear water transition components. In this situation components can provide support for one another and if full capacity of one component is reached, another component can take over and recollect the 


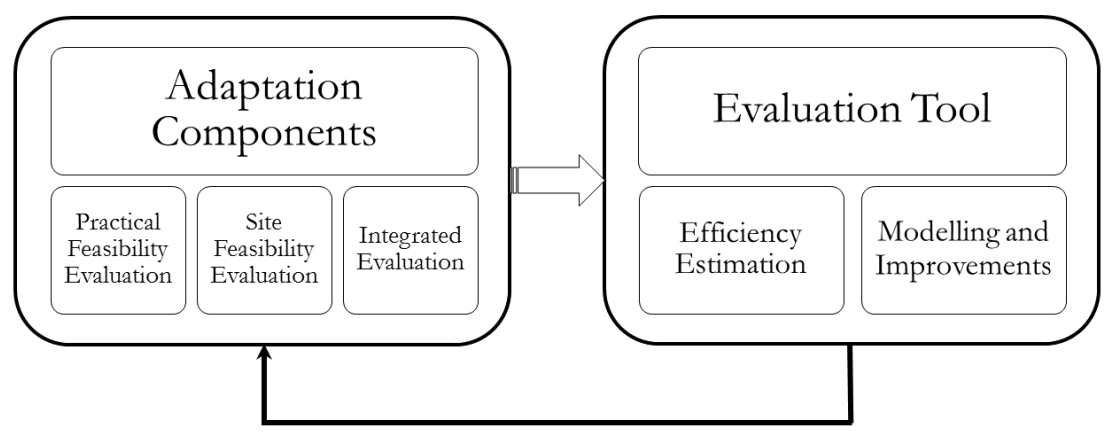

Figure 3: BGI feasibility set up.

water $[29,30]$. During extreme rainfalls, when all existing storage capacity in the system is to be deployed, connectivity is very important [29]. Planning the joining components and their spatial positioning is very important to avoid bottlenecks and other unwanted flow phenomena [29]. As an integrated evaluation, we have to compute, the total scores of the BGI on practical feasibility and site feasibility to estimate their complementarity to the existing system capacities.

\subsection{Efficiency estimation}

Based on Figure 3, adaptation components will be applied to a project area and its efficiency will be evaluated by efficiency valuation device. An Adaptation support tool such as Public Participation Geo-Information Systems (PPGIS) or Planning Support Systems (PSS) [31-33], should directly compute estimates of expenditures, benefits, and multiple parameters of the ecosystem. This evaluation provides users with a comparison of project area operations before and after the implementation of BGI.

\subsection{Modelling and improvement}

As soon as the users have carefully chosen two or three practicable alternative adaptation components through efficiency estimation technique, water administrators can provide more comprehensive investigation of the water quantity and quality dynamics during extreme precipitation, drought, and flooding while, designers can create more comprehensive plans. Based on these investigations, they can further improve their plans and the efficiency of their estimations. 


\section{Conclusion}

Water resource management in a changing climate will be very complex, because of increased scarcity and increased competition between users (domestic, industrial, agricultural and environmental). These new challenges alter the role of water-resource managers and planners. They will have to incorporate landuse planning with blue-green bodies, generating groundwater, and surface runoff recharge in their future plans. The ultimate task is to manage the partitioning of rainfall for humans and ecosystems across regional scales. A key new component of water governance will be providing water for human activities while paying attention to safeguarding the water for vital aquatic and terrestrial ecosystems. It is considered not only as a means of preserving ecological functions but as a strategy for building resilience when faced with extreme events such as floods [34].

Flood risk management is dealing with the governance of such systems. It covers a holistic and continuous assessment, social analysis, and reduction of flood risk. Hereby, 'holistic' states to whole flood risk system and 'continuous' states the need for its ongoing monitoring and steering by the community [35].

Unlike the short-term management of running flood events, long-term planning emphasizes the construction, controlling, and implementation of policies for future flood events. It is devoted to concrete actions in the medium term (up to 10-20 years) or more explorative for an explicit long term (up to 50-100 years). The longtime planning has to take into account that some elements of flood risk systems are a subject to a significant dynamic through external and internal drivers as well. For example, climate change affects the flood hazards or changes in land use has an effect on the vulnerability to flood. Therefore, water resources managers need to discover the system's dynamic and its effects so they can reflect the suitability of alternative strategies under the situation of an unreliable future. Also, the predictability of the future is restricted which it causes certain requirements for the management process itself [35].

The creative use of Blue-Green Infrastructure is one of the most promising actions for adaptation to rapidly changing human and environmental circumstances. This needs to be recognised in the planning process, especially in the formulation of Regional (Spatial) Development Strategies. Above all, the development of this important concept can be a key component for: (i) mitigating observed and likely future climate impacts, (ii) securing water for regional and agricultural development, and (iii) creating jobs for Regional Australia. The scale and inter-connectedness of the problematic situations confronting regional systems, its human communities and natural ecosystems are such that only wellthought systemic intervention practices, which are ethical, take account of multiple viewpoints and are sensitive to the ecology we are a part of, would offer hope of successfully tackling them [4]. 


\section{References}

[1] Mackellar, D., The closed door and other verses. Australasian Authors' Agency, 1911.

[2] Middlemann, M.H., Middelmann, M. \& Australia, G., Natural hazards in Australia: identifying risk analysis requirements. Geoscience Australia, 2007.

[3] Gentle, N., Kierce, S., Nitz, A. et al., Economic costs of natural disasters in Australia. Australian Journal of Emergency Management, The, 16(2), p. 38, 2001.

[4] Faggian, R., Blue-green infrastructure for creating resilient regions, a case study in the Gippsland region, Victoria, Australia, 2014.

[5] Whetton, P.H., Suppiah, R., McInnes, K., Hennessy, K.J. \& Jones, R., Climate change in Victoria: high resolution regional assessment of climate change impacts. Department of Natural Resources and Environment, 2002.

[6] Walsh, K., Allan, R., Jones, R., Pittock, B., Suppiah, R. \& Whetton, P., Climate change in queensland under enhanced greenhouse conditions. First Annual Report, CSIRO Atmospheric Branch, Aspendale, Victoria, Australia, 1999.

[7] Abbs, D., A high resolution modelling study of the effect of climate change on the intensity of extreme rainfall events. Staying afloat: Floodplain Management Authorities of NSW 44th Annual Conference: conference proceedings, Coffs Harbour, NSW. Floodplain Management Authorities of NSW, pp. 17-24, 2004.

[8] Hennessy, K., McInnes, K., Abbs, D., Jones, R., Bathols, J., Suppiah, R., Ricketts, J., Rafter, T., Collins, D. \& Jones, D., Climate change in New South Wales. Part 2: Projected changes in climate extremes, 2004.

[9] Wenger, C., Hussey, K., Pittock, J. et al., Living with floods: key lessons from Australia and abroad. National Climate Change Adaptation Research Facility, Gold Coast, 2013.

[10] Rahman, A., Haddad, K., Ishak, E., Weinmann, E. \& Kuczera, G., Regional flood estimation in Australia: An overview of the study in relation to the upgrade of Australian rainfall and runoff. Flood Management Association, 2010.

[11] Meehl, G.A., Stocker, T.F., Collins, W.D., Friedlingstein, P., Gaye, A.T., Gregory, J.M., Kitoh, A., Knutti, R., Murphy, J.M., Noda, A. et al., Global climate projections. Climate change, 3495, pp. 747-845, 2007.

[12] Bates, B., Kundzewicz, Z.W., Wu, S. \& Palutikof, J., Climate change and water: Technical paper VI. Intergovernmental Panel on Climate Change (IPCC), 2008.

[13] Preston, B.L., Jones, R.N. \& Scientific, C., Climate change impacts on Australia and the benefits of early action to reduce global greenhouse gas emissions. CSIRO Canberra, 2006.

[14] Leary, N., Climate change and adaptation. Earthscan, 2012. 
[15] Field, C.B., Barros, V.R., Mach, K. \& Mastrandrea, M., Climate change 2014: impacts, adaptation, and vulnerability, volume 1. Cambridge University Press, Cambridge, New York, NY, 2014.

[16] Correia, F.N., Da Silva, F.N., Ramos, I. et al., Floodplain management in urban developing areas. Part II. GIS-based flood analysis and urban growth modelling. Water Resources Management, 13(1), pp. 23-37, 1999.

[17] Ghanbarpour, M., Salimi, S. \& Hipel, K., A comparative evaluation of flood mitigation alternatives using GIS-based river hydraulics modelling and multicriteria decision analysis. Journal of Flood Risk Management, 6(4), pp. 319-331, 2013.

[18] Voskamp, I. \& Van de Ven, F., Planning support system for climate adaptation: Composing effective sets of blue-green measures to reduce urban vulnerability to extreme weather events. Building and Environment, 83, pp. 159-167, 2015.

[19] Thorne, C., Lawson, E., Ozawa, C., Hamlin, S. \& Smith, L., Overcoming uncertainty and barriers to adoption of blue-green infrastructure for urban flood risk management. Journal of Flood Risk Management, 2015.

[20] Lawson, E., Thorne, C., Ahilan, S., Allen, D., Arthur, S., Everett, G., Fenner, R., Glenis, V., Guan, D., Hoang, L. et al., Delivering and evaluating the multiple flood risk benefits in blue-green cities: an interdisciplinary approach. Flood Recovery, Innovation and Response IV, 184, p. 113, 2014.

[21] Fryd, O., Dam, T. \& Jensen, M.B., A planning framework for sustainable urban drainage systems. Water Policy, 14(5), pp. 865-886, 2012.

[22] Fletcher, T., Andrieu, H. \& Hamel, P., Understanding, management and modelling of urban hydrology and its consequences for receiving waters: A state of the art. Advances in Water Resources, 51, pp. 261-279, 2013.

[23] Roldin, M., Fryd, O., Jeppesen, J., Mark, O., Binning, P.J., Mikkelsen, P.S. \& Jensen, M.B., Modelling the impact of soakaway retrofits on combined sewage overflows in a $3 \mathrm{~km} 2$ urban catchment in Copenhagen, Denmark. Journal of Hydrology, 452, pp. 64-75, 2012.

[24] Hamel, P., Daly, E. \& Fletcher, T.D., Source-control stormwater management for mitigating the impacts of urbanisation on baseflow: A review. Journal of Hydrology, 485, pp. 201-211, 2013.

[25] Rodriguez, F., Andrieu, H. \& Morena, F., A distributed hydrological model for urbanized areas-model development and application to case studies. Journal of Hydrology, 351(3), pp. 268-287, 2008.

[26] Fryd, O., Backhaus, A., Birch, H., Fratini, C., Ingvertsen, S.T., Jeppesen, J., Panduro, T.E., Roldin, M., Jensen, M.B. et al., Water sensitive urban design retrofits in Copenhagen-40\% to the sewer, $60 \%$ to the city. Water Sci Technol, 67(9), pp. 1945-1952, 2013.

[27] Bastien, N., Arthur, S., Wallis, S. \& Scholz, M., The best management of suds treatment trains: a holistic approach. Water Science \& Technology, 61(1), 2010. 
[28] Sauerwein, M., Urban soils-characterization, pollution and relevance in urban ecosystems. In: Ecology: Patterns, Processes and Applications, eds Niemelä, J., Breuste, J.H., Elmqvist, T., pp. 45-58. Wiley, 2011.

[29] Villarreal, E.L., Semadeni-Davies, A. \& Bengtsson, L., Inner city stormwater control using a combination of best management practices. Ecological Engineering, 22(4), pp. 279-298, 2004.

[30] Jefferies, C., Duffy, A., Berwick, N., McLean, N. \& Hemingway, A., Sustainable urban drainage systems (SUDS) treatment train assessment tool. Water Science \& Technology, 60(5), 2009.

[31] Geertman, S. \& Stillwell, J., Planning support systems: an inventory of current practice. Computers, Environment and Urban Systems, 28(4), pp. 291-310, 2004.

[32] Malczewski, J., GIS-based land-use suitability analysis: a critical overview. Progress in Planning, 62(1), pp. 3-65, 2004.

[33] te Brömmelstroet, M., Performance of planning support systems: what is it, and how do we report on it? Computers, Environment and Urban Systems, 41, pp. 299-308, 2013.

[34] Falkenmark, M. \& Rockström, J., The new blue and green water paradigm: Breaking new ground for water resources planning and management. Journal of Water Resources Planning and Management, 132(3), pp. 129-132, 2006.

[35] Schanze, J., Long-term planning of flood risk management. Climate Change Impacts on the Water Cycle, Resources and Quality, 25, p. 86, 2006. 